\title{
Silencing a Candidate Nematode Effector Gene Corresponding to the Tomato Resistance Gene Mi-1 Leads to Acquisition of Virulence
}

\author{
Cynthia A. Gleason, Qingli L. Liu, and Valerie M. Williamson
}

Department of Nematology, University of California, Davis

Submitted 13 October 2007. Accepted 17 January 2008.

\begin{abstract}
The $M i-1$ gene in tomato confers effective resistance against several species of root-knot nematode, including Meloidogyne javanica. A strain of $M$. javanica that can reproduce on tomato with $M i-1$ was obtained from a culture of an avirulent strain after greenhouse selection. DNA blots and amplified fragment length polymorphism (AFLP) analysis indicated that the two nematode strains are closely related. Expression patterns visualized as cDNA AFLPs were nearly identical except for a cDNA fragment, $C g-1$, that was present in the avirulent strain but not in the virulent strain. DNA blots showed that $C g-1$ corresponds to a member of a small gene family with one or more copies missing in the virulent strain compared with the avirulent strain. Except for the presence of a histone stem loop near the $3^{\prime}$ end of the transcript, $C g-1$ shows no similarity to other sequences in GenBank. The longest open reading frame is 32 amino acids and initiates at the fourth AUG in the predicted transcript. When nematode juveniles of the $M i$ - 1 -avirulent strain were soaked in dsRNA corresponding to part of the predicted $C g-1$ transcript, they produced progeny that were virulent on tomato carrying the $\mathrm{Mi}-1$ gene, strongly suggesting that $C g-1$ is required in the nematode for $\mathrm{Mi}$-1-mediated resistance.
\end{abstract}

Additional keywords: avirulence, histone hairpin, $R$ gene, sORF-mRNA

Root-knot nematodes (Meloidogyne spp.) are sedentary endoparasites that can damage a wide range of crops and cause billions of dollars in agricultural losses each year (Williamson and Hussey 1996). Planting crops with resistance to plantparasitic nematodes is a preferred form of nematode control due to the toxicity of chemical fumigants and their limited availability (Barker and Koenning 1998; Williamson and Kumar 2006). The tomato gene Mi-l confers resistance to several of the most damaging root-knot nematode species and is widely deployed for nematode control. However, there have

\section{A. Gleason and Q. L. Liu contributed equally to this work.}

Corresponding author: V. M. Williamson; vmwilliamson@ucdavis.edu

Current address of C. A. Gleason: CSIRO Plant Industry, Perth, WA, 6913, Australia.

Current address of Q. L. Liu: Department of Biology, University of North Carolina-Chapel Hill 27599 U.S.A.

* The $e$-Xtra logo stands for "electronic extra" and indicates that four supplementary figures are published online. been several reports of root-knot nematode populations that can infect tomato plants with $\mathrm{Mi}-\mathrm{I}$ (Bost and Triantaphyllou 1987; Eddaoudi et al. 1997; Kaloshian et al. 1996; Riggs and Winstead 1959; Roberts et al. 1995; Tzortzakakis et al. 1999; $\mathrm{Xu}$ et al. 2002). Virulent populations include both field isolates and populations selected on $\mathrm{Mi}$-1-containing tomato in the greenhouse.

The root-knot nematode species Meloidogyne incognita, $M$. javanica, and $M$. arenaria, against which $M i-1$ is highly effective and which are three of the most damaging plant-parasitic nematodes, reproduce exclusively by mitotic parthenogenesis (Castagnone-Sereno 2006; Triantaphyllou 1985). Eggs are produced after mitotic division, resulting in progeny that are predicted to be clonal and making Mendelian analysis of the inheritance of avirulence or virulence impossible. However, these species are widely distributed in agricultural settings, polyphagous, and amenable to selection and adaptive variation (Trudgill and Blok 2001). How these asexual species are able to adapt and evolve genetically is an important question for both evolutionary studies and practical management. So far, the mechanisms for this adaptability in nematodes have not been determined.

As a central part of their innate immune system, plants have a repertoire of resistance genes ( $R$ genes) that protect them from specific pathogens, including viruses, bacteria, fungi, and nematodes (Belkhadir et al. 2004; Dangl and Jones 2001; Martin et al. 2003). Upon recognition of the presence of a specific pathogen-produced effector, the product of what is called an avirulence $(A v r)$ gene, the $\mathrm{R}$ protein initiates an array of active defenses, typically including a rapid, localized cell death, or hypersensitive response, at the site of infection. The large majority of cloned $R$ genes, including $M i-1$, encode proteins having a domain structure including a central conserved region with a nucleotide-binding site and a C-terminal leucine-rich repeat region (Milligan et al. 1998). Avr genes have been cloned from bacteria, viruses, fungi, and oomycetes (Belkhadir et al. 2004; Kamoun 2006) but, so far, none have been identified conclusively from nematodes even though several nematode resistance genes have been isolated (Williamson and Kumar 2006). However, there is genetic evidence that avirulence to specific $R$ genes is inherited as a single dominant trait in some plant-parasitic nematode species (Chen and Roberts 2003; Janssen et al. 1991). Resistance to root-knot nematodes mediated by $\mathrm{Mi}-\mathrm{l}$ is characterized by a localized hypersensitive response triggered within 1 day after nematodes enter the root (Dropkin 1969). This timing and the predicted cytoplasmic localization of the $\mathrm{Mi}-1$ gene product suggest that release of nematode secretions into the host cell cytoplasm may be eliciting the $\mathrm{Mi}$-1-mediated defense response. 
Due to the importance of $M i-1$ for nematode control in tomato, acquisition of virulence on tomato with this gene by nematode populations has been investigated in several studies. For some isolates, virulence was selected in the greenhouse after initiation of the culture from a single egg mass, indicating that it did not come from preexisting variants in the population (Bost and Triantaphyllou 1987; Castagnone-Sereno et al. 1994; $\mathrm{Xu}$ et al. 2002). In several cases, the increase in virulence on $\mathrm{Mi}-\mathrm{l}$ tomato was progressive and increased over generations (Bost and Triantaphyllou 1987; Jarquin-Barbera et al. 1991). There also was evidence that acquisition of virulence carried a fitness cost (Castagnone-Sereno 2006). The acquired virulence to $M i-1$ tomato was stably inherited and maintained even after extended growth on susceptible plants (Castagnone-Sereno et al. 1993).

DNA comparisons using the fingerprinting technique amplified fragment length polymorphism (AFLP) (Vos et al. 1995) on closely related pairs of $M$. incognita strains that differed in virulence revealed loss of a small number of bands in virulent strains (Semblat et al. 2001). A candidate Avr gene map-lwas identified from a band missing in three different virulent strains compared with their avirulent progenitors (Semblat et al. 2001). DNA blots revealed a polymorphism for this gene correlated with avirulence among certain strains of $M$. incognita. Polyclonal antibodies raised to the encoded protein indicated that the map- 1 product was localized to nematode amphids, chemosensory organs at the anterior of the nematode. In further studies, paired avirulent and virulent strains showed reduced expression of several genes in the virulent strains (Neveu et al. 2003). However, functional evidence correlating map- 1 or any of these genes with virulence or avirulence has not been presented.

In this article, we describe a nearly isogenic pair of strains of $M$. javanica that differ in ability to infect tomato with the $M i-1$ gene. We identify a gene, $C g-1$, that is missing in the virulent strain and show that silencing the corresponding transcript in the avirulent strain results in production of nematode progeny that are virulent on tomato with $M i-1$.

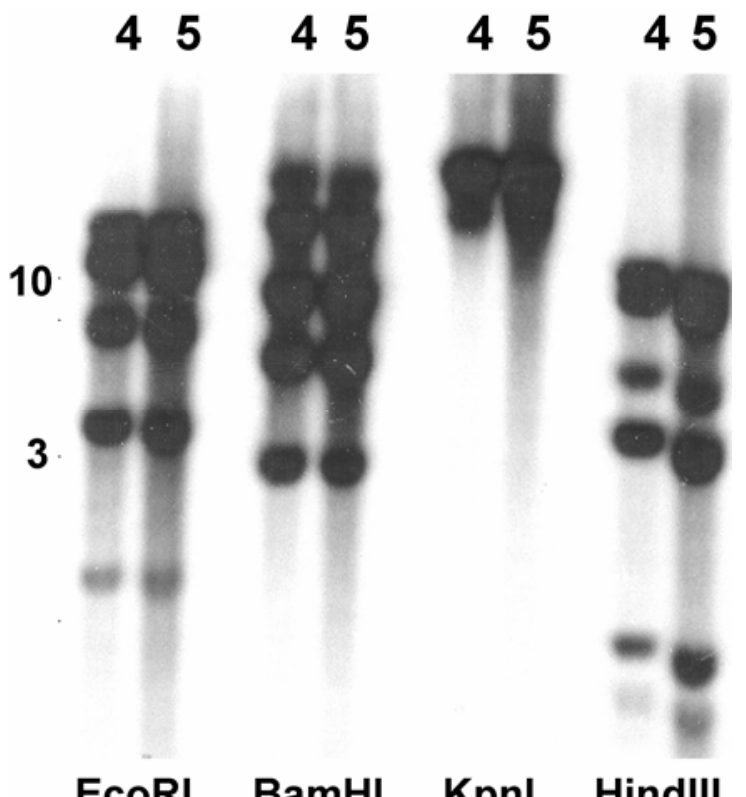

Fig. 1. DNA blot comparisons of VW4 and VW5. DNA from Meloidogyne javanica strains VW4 and VW5 (labeled 4 and 5, respectively) was probed with map-1. Each lane contains $10 \mu \mathrm{g}$ of genomic DNA digested with the indicated restriction enzyme. Numbers on the left indicate positions of markers in kilobases.

\section{RESULTS}

M. javanica strains VW4 and VW5 differ in virulence on tomato with $M i-1$, but are genomically very similar.

After multiple attempts over several years, we recovered one VFNT cherry $(M i-1 / M i-1)$ plant with many galls at 3 months, which corresponds to two generations, after inoculation with VW4, our laboratory strain of $M$. javanica. Progeny from the culture were able to reproduce well on tomato lines carrying

Table 1. Primers used in this work

\begin{tabular}{lll}
\hline Name & \multicolumn{1}{c}{ Sequence $\left(\mathbf{5}^{\prime}\right.$ to $\left.\mathbf{3}^{\prime}\right)$} & \multicolumn{1}{c}{ Source } \\
\hline a1R & AACCTCGCCATTCATTGTC & This work \\
a2 & GGAGATCAGCAATATAAAC & This work \\
a2R & GTTTATATTGCTGATCTCC & This work \\
a3 & GCATTTTCATTGTTCCTTAGGTG & This work \\
a4 & TGAAATCTTAAGACGGCGAGAA & This work \\
& TTC & \\
a5 & GAGCCGTCCATTTTAAACCA & This work \\
a6 & GGGTTAAGGTTGTTGTTGCC & This work \\
a49 & GAAATCTTAAGACGGCGAGAAT & This work \\
SL & CTCGCTCGCCCAGGTTTAATTAC & Lambert et al. 1999 \\
& CCAAGTTTAAG & \\
M1 & CGTGTAACAGAGATGCCAGA & Semblat et al. 2001 \\
M2 & GTGGAGGAACAGTAAGTGAG & Semblat et al. 2001 \\
VAP-F & CTAAATTTCTAAAAACATTTAAA & GenBank BG736958 \\
& TACT & \\
VAP-R & GGATACCAATTTGAACTTGTCA & GenBank BG736958 \\
MSP-F & ATCAATGCTGGTGGACGTCGTA & GenBank BM882968 \\
MSP-R & TGTATTCAATTGGAAGATTCTT & GenBank BM882968 \\
ACT-F & TCAACACGCCTGCCATGTATGTT & GenBank AF532605 \\
ACT-R & AGGATCTTCATCAAGTAGTCGGT & GenBank AF532605 \\
\hline
\end{tabular}

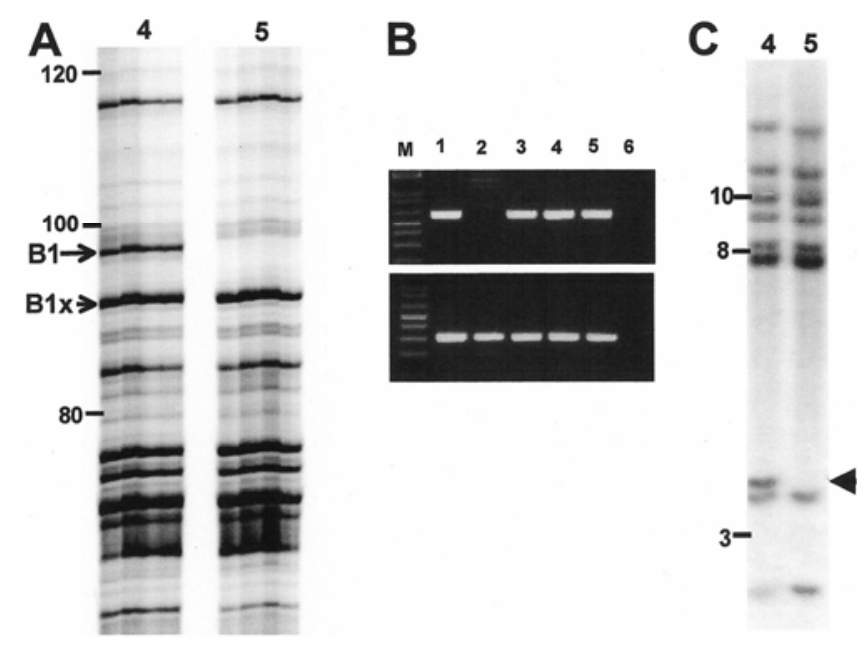

Fig. 2. Comparison of $C g-1$ in strains VW4 and VW5. A, Amplified fragment length polymorphism (AFLP) cDNA polymorphism distinguishing Meloidogyne javanica strains VW4 and VW5. Polymorphisms were produced using AFLP primers E+TAC and M+CTG. Four replicate lanes each of VW4 and VW5 were amplified. Only the portion of the gel containing the polymorphism is shown. Positions are indicated for polymorphic fragment B1 and B1x, the expected fragment generated by amplification of a $\mathrm{Cg}-1$ homolog lacking the diagnostic 6-nucleotide sequence CAATGA. Numbers to the left of gel indicate positions of size markers in nucleotides. B, Polymerase chain reaction products using primers a5 and a6 in upper panel and actin primers ACT-F and ACT-R in lower panel. Lane 1 was amplified from DNA of strain VW4; lane 2, strain VW5; lane 3, strain VW4 isolated from $\mathrm{Mi}$-tomato after treatment with dsRNA a5a6; lane 4, strain VW4 after treatment with dsRNA a4a6; lane 5, VW4 after treatment with a3a6; lane 6, no template control. C, DNA blot comparing VW4 and VW5 DNA probed with $C g-1$ fragment amplified using primers a5 and a6. DNA (10 $\mu$ g from each strain) was cleaved with HindIII. Arrowhead points to band present in strain VW4 that is missing in strain VW5. Numbers on left indicate position of size markers in kilobases. 
$M i-1$. The virulent nematodes were identified as $M$. javanica by isozyme electrophoresis of single females (Esbenshade and Triantaphyllou 1990) and by mitochondrial polymerase chain reaction (PCR) assay (Powers and Harris 1993) and were assigned the strain name VW5.

A blot of DNA from strains VW4 and VW5 digested with restriction endonucleases was hybridized with a probe corresponding to map-1, an amphid-secreted putative Avr gene from M. incognita (Semblat et al. 2001) and revealed no polymorphisms between VW4 and VW5 (Fig. 1). DNA blots were hybridized with several additional low-copy or single-copy probes and, again, no polymorphisms were noted (results not shown). As a more sensitive way to detect DNA polymorphisms, AFLP fingerprint patterns from VW4 and VW5 were compared using nematode DNA digested with either TaqI/AseI or EcoRI/MseI. Over 9,000 fragments were compared after amplification with 91 combinations of TaqI/AseI primers with two selective nucleotides, and approximately 3,700 fragments were compared from 74 combinations of EcoRI/MseI primers.
No reproducible differences in DNA fragment sizes were observed between VW4 and VW5, confirming that these strains are highly similar in DNA sequence.

\section{Identification of a transcript and genomic sequence lacking in virulent strain VW5.}

We compared gene expression patterns of second-stage juveniles (J2) of VW4 and VW5 using cDNA-AFLP. Of the approximately 12,000 fragments compared, only one, B1, revealed a reproducible polymorphism (Fig. 2A). This band was present in the avirulent strain VW4 but absent in the virulent strain VW5. Inserts in five independent clones of the extracted band corresponded to an identical 62-bp sequence.

Inverse PCR using primers a1R and a2R (Table 1) identified a 664-bp fragment of genomic DNA flanking B1. Primers a5 and a6, designed from the genomic DNA sequence, were used to obtain the genomic DNA spanning B1 by PCR. Comparison of the cDNA AFLP and genomic sequences revealed that $\mathrm{B} 1$ corresponded to a portion of the transcript that spans a 64-

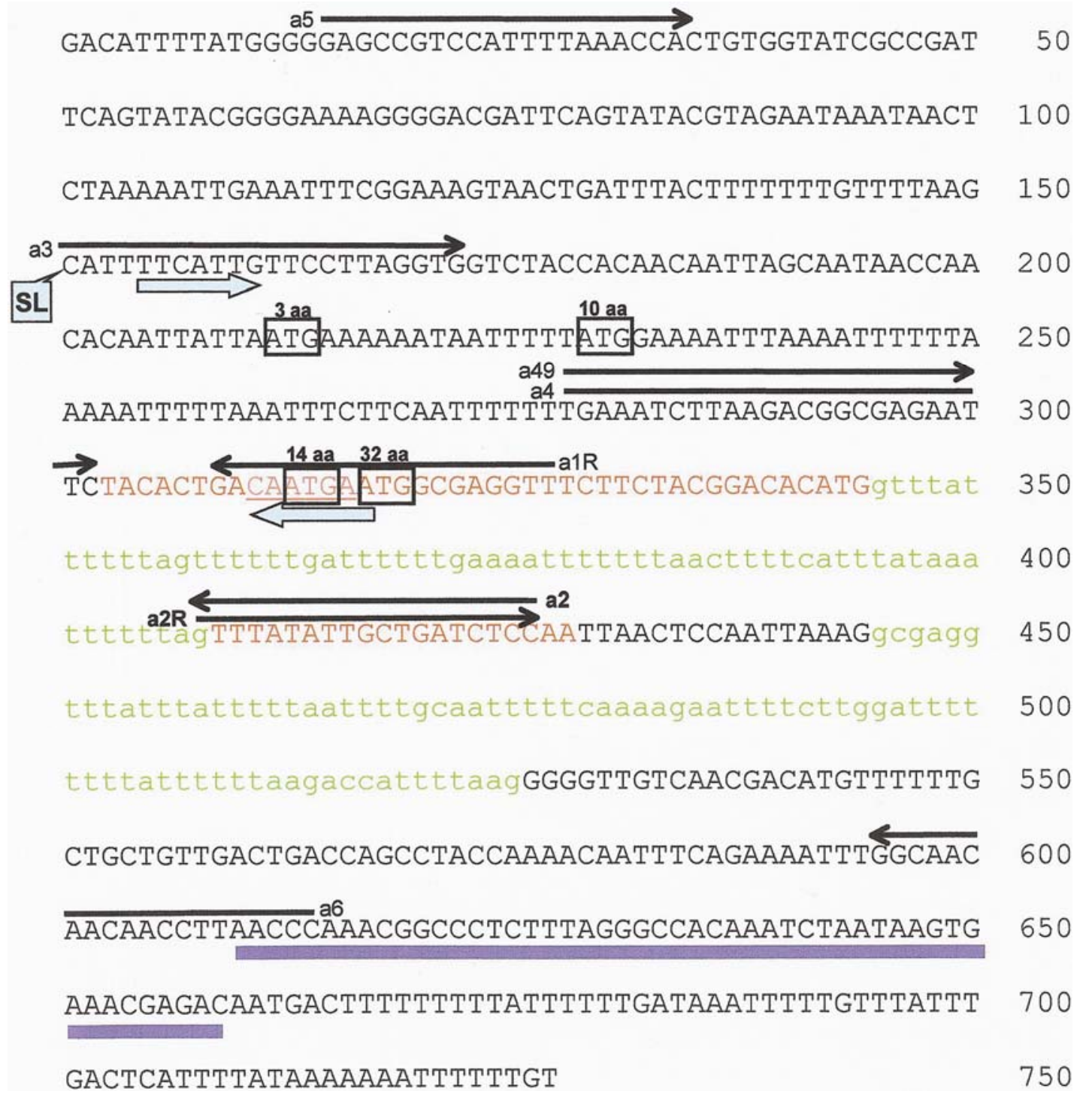

Fig. 3. Genomic DNA sequence corresponding to $C g$ - 1 . The sequence of the amplified fragment length polymorphism cDNA fragment B1, shown in red, was used to obtain the corresponding genomic fragment by inverse polymerase chain reaction. Positions of the spliced leader (SL) and introns (green, lowercase) in the predicted transcript are indicated. Primers described in the text are indicated by black arrows. The sequence CAATGA that is missing in other $C g$ - 1 family members is underlined in red. The ATG that initiates each of the first four open reading frames in the $C g$ - 1 transcript is boxed. The number over the box indicates that number of amino acids in the open reading frame. Light-blue arrows indicate an inverted repeat. Purple bar shows the location of the stemloop sequence that is also found in root-knot nematode histone transcripts. 
nucleotide (nt) intron (Fig. 3). We refer to the derived 727-nt genomic sequence as $C g-1$ in this article. No band was amplified from strain VW5 with primers a5 and a6, suggesting that this strain carries a deletion compared with VW4 (Fig. 2B).

When $C g-1$ was used as a probe on DNA blots of HindIIIdigested VW4 and VW5 DNA, several common fragment sizes were seen; however, a 4-kb fragment that was present in VW4 was absent from VW5 (Fig. 2C). A polymorphic hybridization pattern also was seen with a KpnI digest but no polymorphisms were noted between VW4 and VW5 on blots of DNA digested with DraI, EcoRI, or EcoRV (not shown).

When genomic DNA of strains VW4 and VW5 was amplified using primers a3 and a6, a band of approximately $470 \mathrm{nt}$ was produced for both strains. For each strain, the band was excised and cloned and 10 individual clones were sequenced (Supplementary Figs. S1 and S2). For VW4, nine homologous sequences ranging from 87 to $100 \%$ identity to $C g$ - 1 were obtained. Sequence comparison indicates that at least eight different family members were amplified. However, it is possible that some of the polymorphisms were due to PCR artifacts. Two of the nine sequences contained the signature 6-nt sequence CAATGA that was present in fragment B1. A sequence of 10 clones from VW5 revealed a similar assortment of highly related sequences, except that none carried the signature sequence CAATGA. All sequences missing this 6-nt sequence were simple deletions (alternatively, those with CAATGA could be considered insertions). Taken together, the DNA blots, PCR products from genomic DNA, and sequence analysis support the hypothesis that VW5 has a deletion of one or more copies of a conserved gene family when compared with VW4.

\section{Characterization of $\mathrm{Cg}-1$ transcripts.}

To identify the $3^{\prime}$ end of the $C g-1$ transcript, mRNA was isolated from $M$. javanica VW4 J2 and first-strand cDNA was synthesized using an oligo dT primer. Amplification with primer a4 and oligo dT produced a band of approximately 350 bp. Five clones derived from this band were sequenced and found to correspond to three highly similar transcripts that differed by small insertions and deletions. Only one of these sequences carried the 6-nt sequence CAATGA that was present in cDNA AFLP fragment B1, suggesting that closely related homologs also were expressed. To investigate expression of the gene family members, we amplified first-strand cDNA from VW4 and VW5 J2 with primers a49 and a6. Twenty clones from each strain with inserts of approximately $195 \mathrm{nt}$ were sequenced (Supplementary Figs. S3 and S4). Of 19 homologous sequences obtained from VW4, 4 were identical to $C g-1$ and 1 differed by a single nucleotide (possibly a PCR artifact). However, none of the 14 sequences from cDNA of the virulent nematode strain VW5, although highly similar to the sequence of the predicted $\mathrm{Cg}-1$ transcript, carried the diagnostic CAATGA sequence. The lack of a transcript carrying this 6-bp sequence in strain VW5 is further supported by the absence of a band in the AFLP cDNA gel at the position corresponding to B1. The position of a band shorter by $6 \mathrm{nt}$, as would be expected for copies lacking this signature sequence, is indicated as B1x in Figure 2A. Comparison of the $\mathrm{Cg}-1$ transcript to the genomic sequence indicated that this transcript contained two introns downstream from primer a49 (Fig. 3).

Nematodes are unusual in that they have a short, conserved ribonucleotide sequence, called a spliced leader, ligated to the 5 ' end of many of their transcripts (Blumenthal and Steward 1997). We amplified DNA from a gland-enriched cDNA library generated using a trans-spliced leader and oligo dT primer (Lambert et al. 1999) with spliced leader and a2 primers. A 247-bp product was identified that, except for the intron, perfectly matched a region of $C g-1$ with the splice leader primer trans-spliced into position 151 (Fig. 3). Combining the $5^{\prime}$ and $3^{\prime}$ rapid amplification of cDNA ends (RACE) products predicts a transcript of $456 \mathrm{nt}$. RNA blot analysis of VW4 $\mathrm{J} 2$ revealed a
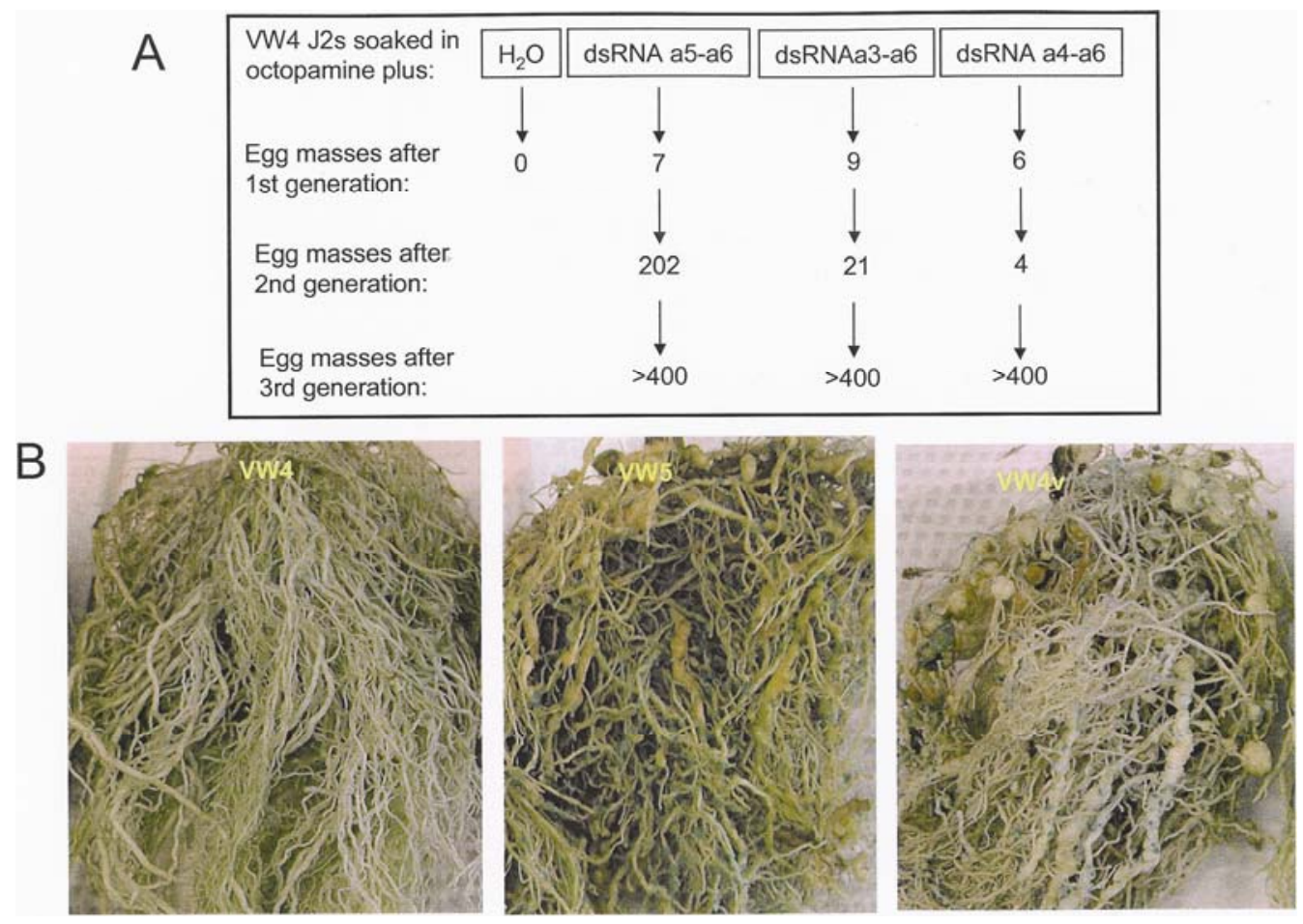

Fig. 4. Phenotype after soaking VW4 in dsRNA corresponding to $C g$-1. A, Total number of egg masses collected from resistant tomato plants after each generation is indicated. VW4 was used as a control at each generation and produced no egg masses. J2s = second-stage juveniles. B, Comparison of root systems of Mi-1-tomato 2 months after infection with VW4, VW5, and VW4v (third generation after soaking in dsRNA a3-a6 and selection on resistant tomato). 
diffuse band consistent with a transcript of approximately this size (results not shown).

\section{Soaking VW4 J2 in dsRNA corresponding to $C g$ - 1 leads to gain of virulence.}

If $C g-1$ is an $A v r$ gene corresponding to $M i-1$, we reasoned that silencing this gene by RNA interference should lead to a gain of virulence. VW4 J2 were soaked in dsRNA corresponding to the region of $C g-1$ between primer pairs a5 and $\mathrm{a} 6$, a 4 and a6, or a 3 and a 6 in the presence of the neurostimulant octopamine, then inoculated onto cv. Motelle (Mi-1/Mi-1) and cv. Moneymaker $(\mathrm{mi} / \mathrm{mi})$ tomato plants. Five weeks postinoculation with $\mathrm{J} 2$, six to nine egg masses were identified and collected from Motelle infected with VW4 J2 treated with dsRNA (Fig. 4A). No egg masses were obtained from VW4 J2 that had been soaked in water. On Moneymaker tomato, both the control and dsRNA-treated VW4 produced $>100$ egg masses.

Approximately $75 \%$ of the eggs from the egg masses collected from $\mathrm{Mi}$-1/Mi-1 tomato were inoculated onto Motelle, and the remainder were inoculated onto Moneymaker. After 5 weeks (one generation), between 4 and 202 egg masses were recovered from Motelle plants (Fig 4A). Each inoculation produced $>50$ egg masses on Moneymaker. No egg masses were observed on Motelle inoculated with VW4. The egg masses from each bioassay then were inoculated onto two Motelle plants. In the next generation, more than 400 egg masses were produced from each type of dsRNA-treated nematodes (Fig. $4 \mathrm{~A}$ and $\mathrm{B}$ ). Additional sequential transfers of egg masses to resistant tomato showed that RNAi-induced virulence was heritable with selection for at least five generations. No obvious decline in pathogenicity (gall or egg-mass size or number) was noted.

To alleviate concern that the virulent nematodes were due to contamination by VW5, the only virulent strain of $M$. javanica in our greenhouses, DNA from J2 of the virulent nematode were amplified with primers a5 and a6, which amplifies a fragment in VW4 but not in VW5. A genomic fragment of the same size as in VW4 was obtained for each J2, confirming that these J2 were not VW5 (Fig. 2B).

To test whether soaking worms in other dsRNA would lead to gain of virulence on tomato with $M i-1, \mathrm{VW} 4 \mathrm{~J} 2$ were soaked in dsRNA corresponding to root-knot nematode genes encoding the major sperm protein (MSP) or venom allergen protein (VAP). In both cases, nematodes still were able to infect and reproduce on susceptible tomato, but no egg masses were obtained on resistant tomato. Experiments in which VW4 J2 were soaked in dsRNA corresponding to each of the three $C g-l$ fragments and controls (MSP and VAP dsRNA and $\mathrm{H}_{2} \mathrm{O}$ ) were repeated twice. No egg masses were produced on resistant tomatoes for any of the controls; however, 6 to 10 egg masses were obtained when $\mathrm{J} 2$ were soaked in dsRNA corresponding to each of the three $\mathrm{Cg}-1$ fragments.

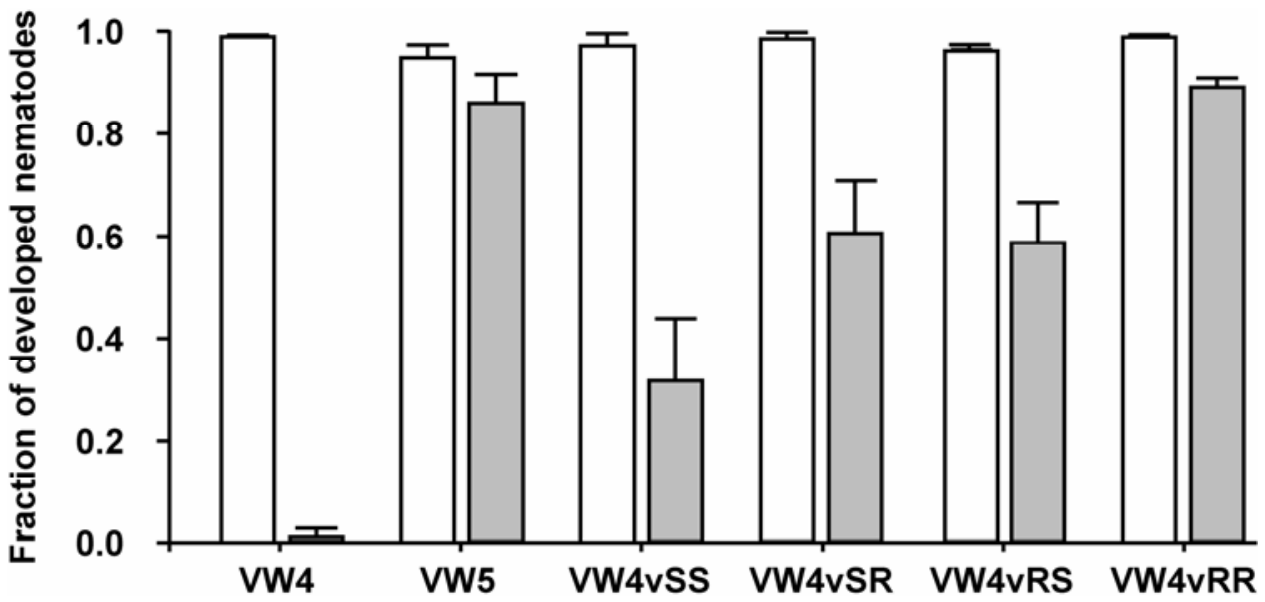

Fig. 5. Stability of virulence in silenced worms. Virulence of progeny of VW4v after two generations on susceptible tomato (SS), on resistant tomato (RR), or on alternating regimes (RS or SR) was assessed as ability of juveniles to develop in a petri dish assay on tomato with or without Mi-1 (Branch et al. 2004). Fractions of developed nematodes on roots of Moneymaker ( $\mathrm{mi} / \mathrm{mi}$, white bars) and Motelle (Mi-1/Mi-1, gray bars) were determined 2 weeks after inoculation of roots. The standard deviation is based on data from three to six petri dishes. The entire set of regimes was repeated twice with similar results.

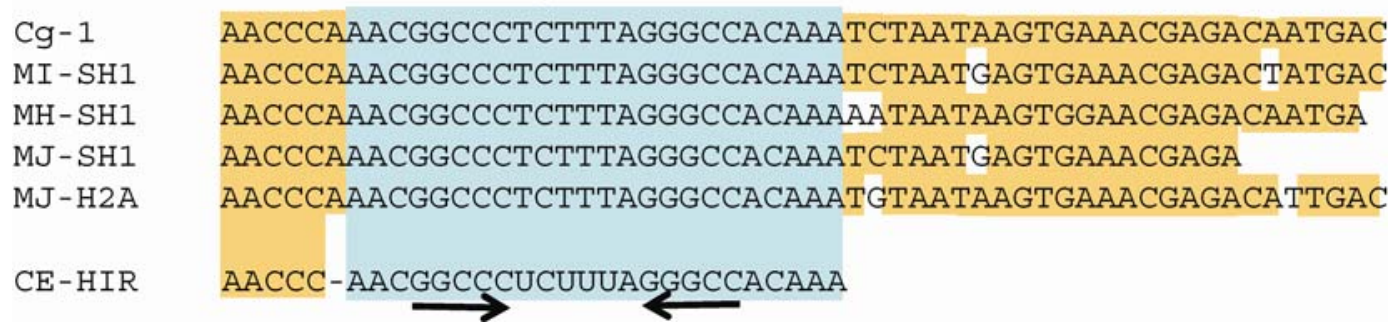

Fig. 6. Comparison of the stem loop region of $C g-1$ to that of other nematode genes. $\mathrm{Cg}-1$ : Sequence near the $3^{\prime}$ end of the $C g-1$ transcript. MI-SH1: Sequence near the $3^{\prime}$ end of an Meloidogyne incognita expressed sequence tag (EST) that does not encode a histone (GenBank accessions CN577907, CK9842080, and CK984267). MH-SH1: Sequence at the 3' end of a nonhistone M. hapla EST (accession CF357095). MJ-SH1: 3' end of an M. javanica nonhistone EST (BG736525). MJ-H2A: 3' end of transcript of histone H2A from M. javanica (CF358954; same sequence as the 3' end of M. incognita H2A, CK984280). CE-HIR: Caenorhabditis elegans histone inverted repeat, the conserved 3 Caenorhabditis end of C. elegans histone transcripts (e.g., NM069731). Inverted arrows mark the classical histone inverted repeat that is conserved in all metazoans. Asterisk marks a $\mathrm{C}$ residue that is required for binding the histone binding protein (Michel et al. 2000). In vertebrates, this residue is U. The complete conservation of the inverted-repeat region is noted by blue shading. Flanking sequences identical to those in $C g-1$ are highlighted in yellow. 
Selection pressure aids maintenance of virulence mediated by RNAi.

Silencing of specific genes by soaking plant-parasitic nematode $\mathrm{J} 2$ in dsRNA has been observed by other groups to last from a few hours to several weeks (Chen et al. 2005; Rosso et al. 2005; Urwin et al. 2002). However, in our case, virulence was maintained for several generations. One possible explanation for the long period of silencing is that the nematodes are being maintained under constant and strong selection. Therefore, even if long-term silencing is a relatively rare event, only those individuals that maintain silencing will be able to infect and reproduce. To test the effect of removing selection, progeny of VW4 treated with dsRNA spanning $C g-1$ a5-a6 at the third generation (referred to here as VW4v) were subjected to four culture regimes: $\mathrm{SS}, \mathrm{VW} 4 \mathrm{v}$ was cultured for two generations on susceptible $(\mathrm{mi} / \mathrm{mi})$ tomato; RR, two generations on resistant $(\mathrm{Mi}-1 / \mathrm{Mi}-\mathrm{l})$ tomato; $\mathrm{RS}$, resistant tomato for one generation, then susceptible tomato for one generation; and SR, susceptible tomato for one generation, then resistant tomato for one generation. After these regimes, eggs were collected and the ability of $\mathrm{J} 2$ that hatched from these eggs to develop on resistant and susceptible tomato roots was compared in a petri dish assay (Branch et al. 2004). The fraction of nematodes that are able to develop on $\mathrm{Mi}-1 / \mathrm{Mi}-1$ tomato was $>90 \%$ after regime RR (constant selection) but was reduced to approximately $30 \%$ after regime SS (Fig. 5). Virulence was intermediate for regimes SR and RS. These results suggest that the virulent phenotype due to RNAi is unstable and that selection is required for prolonged maintenance of the phenotype.

\section{DISCUSSION}

\section{Strains VW4 and VW5 differ by a small deletion.}

Despite a clear difference in virulence on tomato with the resistance gene $M i-1$, we did not detect differences between the two M. javanica strains VW4 and VW5 in our AFLP and initial DNA blot analyses. No polymorphism was seen with a probe from map-1, which previously was shown to be polymorphic in $M$. incognita strains that differ in virulence on $\mathrm{Mi}$ 1-tomato (Semblat et al. 2001). Our findings are consistent with the interpretation that VW5 is a newly emerged strain from a VW4 progenitor, and that the strains are nearly isogenic. Using cDNA-AFLP to search for transcript differences, we identified one transcript corresponding to a gene that we call $\mathrm{Cg}-\mathrm{l}$ that was present in the avirulent strain but lacking in the virulent strain. DNA blot and PCR analyses of $\mathrm{Cg}-1$ are consistent with the hypothesis that a deletion event occurred in the avirulent progenitor strain VW4, giving rise to the virulent strain VW5. Sequences of PCR fragments from VW4 and VW5 suggest that VW4 has one or more copies of $C g-1$ that carry the diagnostic sequence CAATGA, whereas no copies with this sequence were identified in VW5. Taken together, these data indicate that the genomes of these two strains are very similar, possibly differing only in a gene (or a few genes) affecting virulence on $M i-1$. The extent of the deletion is not known; however, it is likely to extend upstream of the $C g-1$ transcript based on the lack of amplification of a fragment from strain VW5 with primers a5 and a6 (Fig. 2B). However, lack of AFLP polymorphisms suggests that the deletion is not a large fraction of the genome, and the DNA blot (Fig. 2C) suggests that only one or a few $C g-1$ family members are lost.

Although we were able to identify only one difference between our virulent and avirulent strains of $M$. javanica, others have identified multiple differences between greenhouseselected virulent strains of $M$. incognita and their progenitors (Neveau et al. 2003; Semblat et al. 2001). There are several possible explanations for the different results. The most obvi- ous is that the species are different. In addition, although, in our case, full virulence developed suddenly, after only a few generations on a resistant plant, in their experiments, virulence developed in a stepwise manner (Jarquin-Barberena et al. 1991). We obtained a virulent strain only once despite several attempts, suggesting that development of virulence in VW4 was a rare event. Some field isolates are virulent on tomato with the $M i-1$ gene even though they are from fields not previously planted in tomato, and populations differ in their potential to develop virulence in the greenhouse (Roberts 1995; Trudgill and Block 2001). Also, some virulent populations show differences in fitness. Therefore, there may be multiple mechanisms that can lead to acquisition of virulence in this parthenogenic parasite. In addition to loss of an avirulence gene, alterations that modify expression of the avirulence gene or increase the nematode's ability to compromise the defense response could result in virulence on tomato with $\mathrm{Mi}-1$.

\section{Cg-1 encodes a transcript with short open reading frames.}

The first three open reading frames (ORF) in the predicted $C g-1$ transcript are 3,10, and 14 amino acids long, respectively (Fig. 3). The longest ORF is 32 amino acids and initiates at the fourth ATG in the transcript. It is possible that one or more of these short peptides could be produced and have a function in virulence, avirulence, or pathogenicity. In fact, a root-knot nematode gene 16D10 that encodes a deduced protein of only 43 amino acids has been shown to function as a ligand for a host transcription factor (Huang et al. 2006). However, although the predicted translation product of $16 \mathrm{D} 10$ includes an N-terminal signal peptide and initiates near the $\mathrm{N}$ terminus of the transcript, the ORF of $C g-1$ are not predicted to contain a signal peptide. Although the 14-amino-acid peptide could not be produced in family members lacking the sequence CAATGA and, thus, would not be produced in VW5, both VW4 and VW5 do produce transcripts encoding the same 32-amino-acid peptide, arguing against a role for this peptide in specificity. However, the presence of the sequence CAATGA in the transcript may alter the secondary structure or the translatability of the transcript because the sequence CAATGAA is present in inverted orientation near the $5^{\prime}$ end of the molecule (Fig. 3, blue arrows), possibly altering the secondary structure of the mRNA or its ability to be translated.

The lack of a definitive ORF suggests that the $C g-1$ transcript may be a noncoding RNA, perhaps with a role as a regulatory molecule in the nematode or in the host. Transcripts with short ORF (sORF-mRNAs) are widespread in plants, animals, and bacteria (Basrai et al. 1997; Gultyaev and Roussis 2007; Hanada et al. 2007; Kondo et al. 2007). Several of the corresponding genes have been shown to have important functions but, in most cases, it is unclear whether the sORF encoded by these genes or the transcript itself is responsible for the activity. In fact, in one of the best-studied examples, the plant gene enod40, it may be both. The early nodulation plant gene enod 40 was assumed to be a nontranslatable RNA because it lacked a significant ORF, could form a stable secondary structure, and did not produce detectable in vitro translation products (Crespi et al., 1994). More recently, researchers showed that enod40 could be translated during in vitro experiments and that two of the enod 40 -encoded peptides from Glycine max could bind sucrose synthase in vitro (Rohrig et al. 2002). There also is evidence that the highly structured transcript of enod 40 binds a nuclear RNA binding protein and is involved in its relocalization during nodule development (Campalans et al. 2004). Analyses of enod40 and homologues in different plant species suggest that this gene is multifunctional and that perhaps both the transcripts and encoded peptides have functions (Gultyaev and Roussis 2007). 
A BLASTN search using the predicted $C g-1$ transcript of available expressed sequence tags (EST) revealed a 56-nt block of sequence with high similarity to the $3^{\prime}$ end of multiple nematode EST. The majority of these sequences correspond to histone transcripts and this sequence carries a stem-loop motif that is identical to that found in the $3^{\prime}$ untranslated region of Caenorhabditis elegans histone transcripts (Fig. 6). When this region is excluded from $C g-1$, no similarity to histone genes or to any other genes was found in the database. Transcripts of histone genes of animals (but not plants) are the only eukarytic mRNAs that are not polyadenylated (Marzluff 2005). Their transcripts can be processed at their $3^{\prime}$ end just after the conserved stem loop, sometimes called the histone hairpin. A novel RNA binding protein, the stem-loop binding protein, binds to this stem loop on the histone transcript. This binding initiates an elaborate processing pathway that leads to the cleavage of the histone mRNA just $3^{\prime}$ to the stem loop.

Our EST database search identified other short cDNA sequences from root-knot nematode species that carry the histone inverted repeat but do not encode histones (Fig. 6). Except for the histone inverted repeat region, these EST do not resemble $\mathrm{Cg}-\mathrm{l}$ in sequence. However, they also appear to correspond to sORF-mRNAs and are initiated by a trans-spliced leader sequence. Interestingly, all sequences with the histone inverted repeat in the genome of $C$. elegans are preceded by histone genes (I. Korf, personal communication). Thus, sORF-mRNAs with histone inverted repeats represent a novel type of transcript so far found only in root-knot nematodes. In C. elegans, histone transcripts are predicted to carry both the inverted repeat and a polyadenylation site in their $3^{\prime}$ untranslated region. Although the majority of isolated histone transcripts are cleaved 3 to $6 \mathrm{nt}$ after the inverted repeat, some do carry a polyA tail (Keall et al. 2007). Thus, if cleavage of the transcript occurs for $C g-1$ and other transcripts with histone stem loop structures as it does for $C$. elegans histone genes, most transcripts would be predicted to lack polyA tails and, thus, be underrepresented in cDNA libraries.

\section{Evidence that $\boldsymbol{C g}-\mathbf{1}$ is an $\mathbf{A v r}$ gene corresponding to $\mathrm{Mi}-\mathbf{1}$.}

Our current hypothesis is that the $C g-1$ gene product mediates recognition of the nematode by the $M i-1$ gene. The presence of $C g-1$ family members with the sequence CAATGA correlates with avirulence when $M$. javanica strains VW4 and VW5 are compared, consistent with this hypothesis. In addition, DNA blots with $C g-1$ as probe identify several hybridizing bands in $M$. incognita, which is recognized by tomato with $M i-1$, but no copies were detected in M. hapla, which is not constrained by Mi-1-mediated resistance (Gleason 2003). This suggests that the $C g-1$ gene family may be restricted to species protected by $M i$-1-mediated resistance.

Our finding that $M$. javanica strain VW4 gains virulence after being soaked in dsRNA derived from $\mathrm{Cg}-\mathrm{I}$ is the strongest evidence that this is the nematode $A v r$ gene corresponding to $M i-1$. This result was obtained in three independent experiments, each time using dsRNA of three different lengths, a5 to a6, a4 to a6, and a3 to a6, from the $C g-1$ transcript. Soaking the nematodes in dsRNA corresponding to other nematode genes did not result in a gain of virulence, indicating that the gain of virulence after dsRNA treatment is sequence specific. Only a few individuals were able to develop on resistant tomato in the first generation after soaking. A possible explanation for this is that silencing was inefficient or not sufficient in most of the nematodes. Alternatively, because the resistance response is initiated soon after infection, it may be that the $C g-1$ gene product is present before soaking and sufficiently stable that it was not depleted when the nematodes infected the plant. Consistent with this, reproduction on resistant tomato was increasingly successful in the following generations.

Our experiments indicate that the gain in virulence on tomato with the $M i-1$ gene after soaking nematodes in dsRNA corresponding to $C g-1$ could be maintained for several generations, whereas work of others has indicated that RNA silencing is generally short lived. In C. elegans, phenotypes generated by RNAi usually last only a few generations. However, recent work with C. elegans has shown that, in this nematode, a single episode of RNAi treatment can induce transcriptional silencing that is inherited indefinitely in the absence of the original trigger (Vastenhouw et al. 2006). We suggest that the apparent longterm silencing that we see is due to the strong selection exerted by the $M i-1$ gene. That is, if $C g-1$ were responsible for $M i-1-$ mediated recognition, one would expect those individuals that express $C g-1$ to be recognized by $M i-1$ triggering the resistance response; only nematodes that remain silenced should be able to infect and reproduce. To test this hypothesis, we subjected virulent progeny of VW4 treated with dsRNA spanning $C g-1$ to additional passage with and without selection. The fraction of nematodes that are able to develop on $\mathrm{Mi}-1 / \mathrm{Mi}-1$ tomato was $>90 \%$ after continued selection but was reduced to approximately $30 \%$ after two passages on susceptible tomato. This result is consistent with our hypothesis that silencing was lost in some progeny but persisted due to the strong selection imposed by the $M i-1$ gene. Consistent with this hypothesis, we were able to amplify fragments of cDNA in progeny of silenced worms using primers a49 and a6 and to show by sequence analysis that these fragments corresponded to $\mathrm{Cg}-\mathrm{I}$ and other family members (results not shown). This result indicates that either some worms in the population are expressing $C g-1$, as would be expected due to the instability of the phenotype, or the silencing is not complete. Unfortunately, we have not yet been successful in obtaining quantitative data on transcript levels of $C g-1$. Thus, we cannot verify or determine the extent of transcript reduction in the treated nematodes. It remains a formal possibility that dsRNA corresponding to $C g-1$ is silencing a different nematode gene. However, dsRNA from other nematode genes that we tested did not result in acquisition of virulence on tomato with $M i-1$.

\section{Toward understanding the role of $\mathrm{Cg}-\mathrm{I}$ in the nematode and in recognition by the host.}

The $C g-1$ gene family is present in approximately nine highly conserved copies in $M$. javanica, none of which have a known function. Because of the high sequence similarity of family members, it is possible that the dsRNA treatments we carried out affected expression of the entire gene family. We observed no obvious loss of pathogenicity compared with VW4 on susceptible tomato, suggesting that this family does not have a major effect on infection and reproduction on tomato plants under our greenhouse conditions. It is possible that pathogenicity is reduced under field conditions or on another host. In fact, a strain of $M$. incognita that was virulent on tomato with $M i-1$ has been reported to have lost virulence on pepper (Castagnone-Sereno et al. 1992).

The novel transcript structure, including the histone inverted repeat, high similarity of family members, and ambiguous ORF have opened numerous areas of inquiry but also have made investigation of this unusual gene family difficult. So far, it is not clear whether the $C g-1$ transcript itself or the encoded peptide is responsible for the avirulence. In some cases where $A v r$ and $R$ gene pairs have been studied, direct interaction between the Avr gene product and the pathogen has been demonstrated (Dodds et al. 2006; Jia et al. 2000). However, in other cases, the recognition is more indirect, involving intermediary molecules in the host (Dangl and McDowell 2006). For other 
plant-pathogen interactions, expression of an $A v r$ gene in the host with or without the corresponding $R$ gene has been informative (Catazanti et al. 2007; Nimchuk et al. 2003). However, for $C g-1$, thus far it is unclear what the gene product is or where it acts. The $C g-1$ product, which could be a positive regulator of an elicitor in the nematode or be a translocated product, could interact directly or indirectly with $M i-1$ or otherwise modulate its activity. Further analyses of this unusual gene family should increase our understanding of this important but understudied plant parasite and its sophisticated, biotrophic interaction with a wide range of hosts.

\section{MATERIALS AND METHODS}

\section{Nematode strains.}

$M$. javanica strain VW4 was reared on the susceptible tomato cv. UC82 whereas strain VW5 was maintained on resistant tomato cv. VFN8 or VFNT. For AFLP work, nematodes were produced in hydroponic culture as described by Lambert and associates (1992). J2 were collected and allowed to crawl through eight kimwipe tissue layers into a solution containing $0.5 \%$ streptomycin sulfate and $0.5 \%$ Penicillin G.

\section{AFLP markers.}

DNA extraction was carried out as previously described (Liu and Williamson 2006). Genomic nematode DNA (250 ng) was digested with two different restriction enzymes, EcoRI and MseI or TaqI and AseI, and the AFLPs were performed essentially as described by Vos and associates (1995) using combinations of TaqI/AseI and EcoRI/MseI primers.

cDNA-AFLP analysis and cloning cDNA-AFLP fragments.

Nematode mRNA was isolated from J2 using Dynabeads (Invitrogen, Carlsbad, CA, U.S.A.), following the manufacturer's protocol. The first strand was synthesized using SuperscriptII reverse transcriptase (Invitrogen). The second strand was synthesized by adding $1 \times$ cDNA second-strand buffer (350 mM Tris-HCl, pH 7.4; $40 \mathrm{mM} \mathrm{MgCl}_{2} ; 10 \mathrm{mM}$ $\left(\mathrm{NH}_{4}\right)_{2} \mathrm{SO}_{4}$; and $30 \mathrm{mM}$ dithiothreitol), $0.25 \mathrm{mM}$ dNTPs, $10 \mathrm{U}$ of DNA Polymerase I (Invitrogen), and $2 \mathrm{U}$ of RNaseH (Invitrogen) to the first-strand reaction. This mixture was incubated for $2 \mathrm{~h}$ at $16^{\circ} \mathrm{C}$ followed by two phenol/chloroform extractions and ethanol precipitation.

cDNA-AFLP analysis was carried out using a protocol adapted from Bachem and associates (1996). The nematode cDNA was digested with either EcoRI and MseI or TaqI and AseI. The area corresponding to the polymorphic cDNA-AFLP fragment was excised from the acrylamide gel, cloned, and sequenced as previously described (Liu and Williamson 2006).

\section{DNA blots.}

Nematode genomic DNA (10 $\mu \mathrm{g})$ was used for each lane. Primers M1 and M2 were used to produce a probe corresponding to map-1 (Semblat et al. 2001). The PCR products were radiolabeled using NEN multiprime labeling system and ${ }^{32} \mathrm{P}$ dCTP. Unincorporated nucleotides were removed with Clontech Chromaspin 10 columns. The probe was hybridized to a Nytran filter using standard protocols (Sambrook and Russell 2001).

\section{Inverse PCR, reverse-transcriptase PCR, and PCR amplifications.}

VW4 DNA $(1 \mu \mathrm{g})$ was digested with $20 \mathrm{U}$ of TaqI (New England Biolabs, Ipswich, MA, U.S.A.) for $4 \mathrm{~h}$ at $37^{\circ} \mathrm{C}$. A ligation reaction was carried out in $500 \mu$ l of total volume containing the DNA with $680 \mathrm{U}$ of T4 DNA ligase (New England Biolabs) and $1 \times$ T4 ligase buffer (New England Biolabs) and incubated overnight at $16^{\circ} \mathrm{C}$. The DNA was ethanol precipitated and resuspended in $10 \mu \mathrm{l}$ of water. PCR with primers $\mathrm{a} 1 \mathrm{R}$ and $\mathrm{a} 2 \mathrm{R}$ was performed in a $25-\mu \mathrm{l}$ reaction volume $(1 \times$ PCR buffer, $0.2 \mathrm{mM}$ dNTPs, $0.2 \mathrm{pM}$ a1R primer, $0.2 \mathrm{pM}$ a2R primer, and $0.5 \mathrm{U}$ of AmpliTaq [Applied Biosystems, Foster City, CA, U.S.A.]) for 35 cycles of $1 \mathrm{~min}$ at $94^{\circ} \mathrm{C}, 1 \mathrm{~min}$ at $50^{\circ} \mathrm{C}$, and $3 \mathrm{~min}$ at $72^{\circ} \mathrm{C}$. The PCR products were cloned into a pGemT-easy vector (Promega Corp., Madison, WI, U.S.A.). Clones with the expected size insert were sequenced.

Amplification using primers a5 and a6 for PCR and reversetranscriptase (RT)-PCR was as follows: 1 cycle at $94^{\circ} \mathrm{C}$ for 3 min; 30 cycles of $94^{\circ} \mathrm{C}$ for $30 \mathrm{~s}, 50^{\circ} \mathrm{C}$ for $30 \mathrm{~s}$, and $72^{\circ} \mathrm{C}$ for $30 \mathrm{~s}$; and 1 cycle of $72^{\circ} \mathrm{C}$ for $10 \mathrm{~min}$.

\section{3' RACE.}

The 3' RACE experiments were performed using cDNA synthesized using the GeneRacer System (Invitrogen). Approximately $200 \mathrm{ng}$ of mRNA was incubated with $400 \mathrm{ng}$ of GeneRacer Oligo(dT) primer and incubated at $70^{\circ} \mathrm{C}$ for $5 \mathrm{~min}$. This was used in a reaction containing $25 \mathrm{mM}$ each $\mathrm{dNTP}, 1 \times$ RT buffer, $5 \mathrm{U}$ of AMT/RV, and $20 \mathrm{U}$ of RNase inhibitor. The mixture was incubated at $42^{\circ} \mathrm{C}$ for $1 \mathrm{~h}$ and $94^{\circ} \mathrm{C}$ for $2 \mathrm{~min}$. The resulting cDNA then was diluted twofold with water.

The 3' RACE was performed using $0.2 \mu \mathrm{M}$ GeneRacer 3' primer and $0.2 \mu \mathrm{M}$ either a3 or a4 primer. The $25-\mu 1$ reaction contained $1 \times$ ThermoZyme PCR buffer, $0.2 \mathrm{mM}$ dNTPs, and $0.5 \mathrm{U}$ of ThermoZyme DNA polymerase. The reaction was carried out as follows: 1 cycle at $94^{\circ} \mathrm{C}$ for $2 \mathrm{~min} ; 5$ cycles at $94^{\circ} \mathrm{C}$ for $30 \mathrm{~s}, 62^{\circ} \mathrm{C}$ for $30 \mathrm{~s}$, and $72^{\circ} \mathrm{C}$ for $3 \mathrm{~min} ; 5$ cycles at $94^{\circ} \mathrm{C}$ for $30 \mathrm{~s}, 58^{\circ} \mathrm{C}$ for $30 \mathrm{~s}$, and $72^{\circ} \mathrm{C}$ for $3 \mathrm{~min}$; and 20 cycles at $94^{\circ} \mathrm{C}$ for $30 \mathrm{~s}, 56^{\circ} \mathrm{C}$ for $30 \mathrm{~s}$, and $72^{\circ} \mathrm{C}$ for $3 \mathrm{~min}$. The PCR products were separated on a $1 \%$ agarose gel. The reaction with $3^{\prime}$ primer and a4 produced a single band and this was purified from the gel using Life Technologies CONCERT Rapid Gel Extraction System (Life Technologies, Gaithersburg, MD, U.S.A.). The purified cDNA was reamplified using the GeneRacer 3' primer and a4, and the PCR product was cloned into a TOPO TA-cloning vector (Invitrogen).

\section{5' RACE.}

A gland-specific $M$. javanica library was reamplified using primers SL1B and LMDB (Table 1). For the 5' RACE experiments, the PCR mixture contained 10 pmoles each of primers SL1B and a2, 1× PCR buffer (Applied Biosystems), $0.2 \mathrm{mM}$ dNTPs, $0.5 \mathrm{U}$ of Amplitaq DNA polymerase (Applied Biosystems), and $0.5 \mu \mathrm{l}$ of reamplified gland library in $25 \mu \mathrm{l}$ of total volume. The PCR was performed as follows: $94^{\circ} \mathrm{C}$ for $3 \mathrm{~min}$; 35 cycles of $94^{\circ} \mathrm{C}$ for $30 \mathrm{~s}, 50^{\circ} \mathrm{C}$ for $30 \mathrm{~s}$, and $72^{\circ} \mathrm{C}$ for $3 \mathrm{~min}$; and 1 cycle of $72^{\circ} \mathrm{C}$ for $15 \mathrm{~min}$. The PCR product was electrophoretically separated on an agarose gel and the single band was purified from the agarose using the Life Technologies CONCERT Rapid Gel Extraction Kit and cloned into a pGemT-easy vector. The ligation was used to transform DH5 $\alpha$ bacteria. Plasmid isolation was performed using CONCERT Plasmid Purification Kit. Clones containing insert were sequenced at the Division of Biological Sciences sequencing facility on the University of California-Davis campus.

RNAi.

To generate dsRNA, fragments of nematode genes of interest were cloned into the vector Litmus38i (New England Biolabs), which has opposing dual T7 promoters. $C g-1$ cDNAs were amplified with primers a5-a6, a3-a6, and a4-a6 and cloned into pGemT-easy vector. Plasmids were digested with PstI and $S p h I$ to release the inserts, then ligated into a Litmus $38 \mathrm{i}$ vector (New England Biolabs) that was digested with the same restriction enzymes. The plasmid was isolated from 3-ml over- 
night cultures using the Qiagen plasmid miniprep kit. PCR was performed to amplify the inserts using a universal T7 primer and a standard PCR protocol. The amplified inserts were purified using the Wizard PCR DNA purification kit (Promega Corp.), concentrated by Amicon-30 (Millipore, Billerica, MA, U.S.A.), and used as template for dsRNA synthesis. dsRNA was produced using the T7 RiboMax dsRNA in vitro transcription kit (Promega Corp.). In a 400- $\mu$ l reaction, $1 \times$ Ribomax buffer, $10 \mu$ l of T7 enzyme (Promega Corp.) was added to $24 \mu \mathrm{g}$ of PCR product. The reaction was incubated for $3 \mathrm{~h}$ at $37^{\circ} \mathrm{C}$ and $15 \mathrm{~min}$ at $65^{\circ} \mathrm{C}$, then slowly cooled to room temperature. The RNA concentration was measured fluorimetrically.

Surface-sterile $\mathrm{J} 2$ were suspended in sterile $\mathrm{H}_{2} \mathrm{O}$, and15,000 $\mathrm{J} 2$ were mixed with $10 \mathrm{mM}$ Octopamine (Sigma-Aldrich, St. Louis) and dsRNA at $0.5 \mathrm{mg} / \mathrm{ml}$, incubated for $48 \mathrm{~h}$ at room temperature, then collected by centrifugation and rinsed with water. For the control experiment, approximately 10,000 J2 were mixed with either $10 \mathrm{mM}$ Octopamine in sterile $\mathrm{H}_{2} \mathrm{O}$ or sterile $\mathrm{H}_{2} \mathrm{O}$ alone and incubated as above. Approximately $1,500 \mathrm{~J} 2$ were inoculated onto each of eight Motelle $(\mathrm{Mi} / \mathrm{Mi})$ plants. Two Moneymaker ( $\mathrm{mi} / \mathrm{mi}$ ) plants were inoculated with 1,500 J2. Plant roots were checked for egg masses 35 days after inoculation.

For silencing controls, dsRNA corresponding to VAP was produced using primers VAP-F and VAP-R derived from the $M$. javanica EST sequence, and corresponding to major sperm protein was produced using primers MSP-F and MSP-R (Table 1).

\section{ACKNOWLEDGMENTS}

We thank K. Lambert for the cDNA library. This research was supported by the National Research Initiative of the United States Department of Agriculture Cooperative State Research, Education and Extension Service, grant number 2001-35302-10135 and by National Science Foundation award IOB-05-20824 to V. M. Williamson.

\section{LITERATURE CITED}

Bachem, C. W. B., Van Der Hoeven, R. S., De Bruijn Steef, M., Vreugdenhil, D., Zabeau, M., and Visser, R. G. F. 1996. Visualization of differential gene expression using a novel method of RNA fingerprinting based on AFLP: Analysis of gene expression during potato tuber development. Plant J. 9:745-753.

Barker, K. R., and Koenning, S. R. 1998. Developing sustainable systems for nematode management. Annu. Rev. Phytopathol. 36:165-205.

Basrai, M. A., Hieter, P., and Boeke, J. D. 1997. Small open reading frames: beautiful needles in the haystack. Genome Res. 7:768-771.

Belkhadir, Y., Subramanian, R., and Dangl, J. L. 2004. Plant disease resistance protein signaling: NBS-LRR proteins and their partners. Current Opin. Plant Biol. 7:391-399.

Blumenthal, T., and Steward, K. 1997. RNA processing and gene structure. Pages 117-145 in: C. elegans II. D. L. Riddle, ed. Cold Spring Harbor Laboratory Press, Cold Spring Harbor, NY.

Bost, S. C., and Triantaphyllou, A. 1987. Genetic basis of the epidemiological effects of resistance to Meloidogyne incognita in tomato cultivar Small Fry. J. Nematol. 44:540-544.

Branch, C., Hwang, C. F., Navarre, D. A., and Williamson, V. M. 2004. Salicylic acid is part of the $\mathrm{Mi}$-1-mediated defense response to rootknot nematode in tomato. Mol. Plant-Microbe Interact. 17:351-356.

Campalans, A., Kondorosi, A., and Crespi, A. 2004. Enod40, a short open reading frame-containing $\mathrm{mRNA}$, induces cytoplasmic localization of a nuclear RNA binding protein in Medicago truncatula. Plant Cell 16:1047-1059.

Castagnone-Sereno, P. 2006. Genetic variability and adaptive evolution in parthenogenetic root- knot nematodes. Heredity 96:282-289.

Castagnone-Sereno, P., Bongiovanni, M., and Dalmasso, A. 1992. Differential expression of root-knot nematode resistance genes in tomato and pepper-evidence with Meloidogyne incognita virulent and avirulent near-isogenic lineages. Ann. Appl. Biol. 120:487-492.

Castagnone-Sereno P., Bongiovanni, M., and Dalmasso, A. 1993. Stable virulence against the tomato resistance $M i$ gene in the parthenogenetic root-knot nematode Meloidogyne incognita. Phytopathology 83:803-805.
Castagnone-Sereno, P., Wajnberg, E., Bongiovanni, M., Leroy, F., and Dalmasso, A. 1994. Genetic variation in Meloidogyne incognita virulence against the tomato $\mathrm{Mi}$ resistance genes: evidence from isofemale line selection studies. Theor. Appl. Genet. 88:749-753.

Catanzariti, A. M., Dodds, P. N., and Ellis, J. G. 2007. Avirulence proteins from haustoria-forming pathogens. FEMS (Fed. Eur. Microbiol. Soc.) Microbiol. Lett. 269:181-188.

Chen, P., and Roberts, P. A. 2003. Genetic analysis of (a)virulence in Meloidogyne hapla to resistance in bean (Phaseolus vulgaris). Nematology 5:687-697.

Chen, Q., Rehman, S., Smant, G., and Jones, J. T. 2005. Functional analysis of pathogenicity proteins of the potato cyst nematode Globodera rostochiensis using RNAi. Mol. Plant-Microbe Interact. 18:621-625.

Crespi, M., Jurkevitch, E., Poiret, M., d'Aubenton-Carafa, Y., Petrovics, G., Kondorosi, E., and Kondorosi, A. 1994. enod40, a gene expressed during nodule organogenesis, codes for a non-translatable RNA involved in plant growth. EMBO (Eur. Mol. Biol. Organ.) J. 13:50995112.

Dangl, J. L., and Jones, J. D. G. 2001. Plant pathogens and integrated defense responses to infection. Nature 411:826-833

Dangl, J. L., and McDowell, J. M. 2006. Two modes of pathogen recognition by plants. Proc. Natl. Acad. Sci. U.S.A. 103:8575-8576.

Dodds, P. N., Lawrence, G. J., Catanzariti, A. M., The, T., Wang, C. A. Ayliffe, M. A., Kobe, B., and Ellis, J. G. 2006. Direct protein interaction underlies gene-for-gene specificity and coevolution of the flax resistance genes and flax rust avirulence genes. Proc. Natl. Acad. Sci. U.S.A. 103:8888-8893.

Dropkin, V. H. 1969. The necrotic reaction of tomatoes and other hosts resistant to Meloidogyne: reversal by temperature. Phytopathology 59:1632-1637.

Eddaoudi, M., Ammati, M., and Rammah, A. 1997. Identification of the resistance breaking populations of Meloidogyne on tomatoes in Morocco and their effect on new sources of resistance. Fundam. Appl. Nematol. 20:285-289.

Esbenshade, P. R., and Triantaphyllou, A.C. 1990. Isozyme phenotypes for the identification of Meloidogyne species. J. Nematol. 22:10-15.

Gleason, C. A. 2003. Comparison of two strains of Meloidogyne javanica differing in virulence on tomato with the resistance gene $M i$, and identification of a polymorphism that correlates with avirulence. Ph.D. thesis, University of California, Davis.

Gultyaev, A. P., and Roussis, A. 2007. Identification of conserved secondary structures and expansion segments in enod40 RNAs reveals new enod40 homologues in plants. Nucleic Acids Res. 35:3144-3152.

Hanada, K., Zhang, X., Borevitz, J. O., and Li, W.-H. 2007. A large number of novel coding small open reading frames in the intergenic regions of the Arabidopsis thaliana genome are transcribed and/or under purifying selection. Genome Res. 17:632-640.

Huang, G., Dong, R., Allen, R., Davis, E. L., Baum, T. J., and Hussey, R. S. 2006. A root-knot nematode secretory peptide functions as a ligand for a plant transcription factor. Mol. Plant-Microbe Interact. 19:463470 .

Janssen, R., Bakker, J., and Gommers, F. 1991. Mendelian proof for a gene-for-gene relationship between virulence of Globodera rostochiensis and the $H 1$ resistance gene in Solanum tuberosum ssp. andigena CPC 1673. Rev. Nematol. 14:213-219.

Jarquin-Barberena, H., Dalmasso, A., de Guiran, G., and Cardin, M. 1991. Acquired virulence in the plant parasitic nematode Meloidogyne incognita. I. Biological analysis of the phenomenon. Rev. Nematol. 14:261275.

Jia, Y., McAdams, S. A., Bryan, G. T., Hershey, H. P., and Valent. B. 2000. Direct interaction of resistance gene and avirulence gene products confers rice blast resistance EMBO (Eur. Mol. Biol. Organ.) J. 19:4004-4014.

Kaloshian, I., Williamson, V. M., Miyao, G., Lawn, D. A., and Westerdahl, B. B. 1996. "Resistance-breaking" nematodes in California tomatoes. Calif. Agric. 50:18-19.

Kamoun, S. 2006. A catalogue of the effector secretome of plant pathogenic oomycetes. Annu. Rev. Phytopathol. 44:41-60

Keall, R., Whitelaw, S., Pettitt, J., and Müller, B. 2007. Histone gene expression and histone mRNA3' end structure in Caenorhabditis elegans. BMC Mo. Biol. 8:Art. No. 51.

Kondo, T., Hashimoto, Y., Kato, K., Inagaki, S., and Hayashi, S. 2007. Small peptide regulators of actin-based cell morphogenesis encoded by a polycistronic mRNA. Nat. Cell Biol. 9:660-665.

Lambert, K. N., Tedford, E. C., Caswell, E. P., and Williamson, V. M. 1992. A system for continuous production of root-knot nematode juveniles in hydroponic culture. Phytopathology 82:512-515.

Lambert, K. N., Allen, K. D., and Sussex, I. M. 1999. Cloning and characterization of an esophageal-gland-specific chorismate mutase from phytoparasitic nematode Meloidogyne javanica. Mol. Plant-Microbe Interact. 12:328-336. 
Liu, Q. L., and Williamson, V. M. 2006. Host-specific pathogenicity and genome differences between inbred strains of Meloidogyne hapla. J. Nematol. 38:158-164.

Martin, G. B., Bogdanove, A. J., and Sessa, G. 2003. Understanding the functions of plant disease resistance proteins. Annu. Rev. Plant Biol. 54:23-61.

Marzluff, W.F. 2005. Metazoan replication-dependent histone mRNAs: a distinct set of RNA polymerase II transcripts. Curr. Opin. Cell Biol. 17:272-280.

Michel, F., Schumperli, D., and Muller, B. 2000. Specificities of Caenorhabditis elegans and human hairpin binding proteins for the first nucleotide in the histone mRNA hairpin loop. RNA 6:1539-1550.

Milligan, S., Bodeau, J., Yaghoobi, J., Kaloshian, I., Zabel, P., and Williamson, V. M. 1998. The root knot nematode resistance gene $M i$ from tomato is a member of the leucine zipper, nucleotide binding, leucine-rich repeat family of plant genes. Plant Cell 10:1307-1319.

Neveu, C., Jaubert, S., Abad, P., and Castagnone-Sereno, P. 2003. A set of genes differentially expressed between avirulent and virulent Meloidogyne incognita near-isogenic lines encode secreted proteins. Mol. Plant-Microbe Interact. 16:1077-1084.

Nimchuk, Z., Eulgem, T., Holt, B. E., and Dangl J .L. 2003. Recognition and response in the plant immune system. Annu. Rev. Genet. 37:579-609.

Powers, T. O., and Harris, T. S. 1993. A polymerase chain reaction method for identification of five major Meloidogyne species. J. Nematol. 25:1-6.

Riggs, R. D., and Winstead, N. N. 1959. Studies on resistance in tomato to root-knot nematodes and on occurrence of pathogenic biotypes. Phytopathology 49:716-724.

Roberts, P. A. 1995. Conceptual and practical aspects of variability in rootknot nematode related host plant resistance. Annu. Rev. Phytopathol. 33:199-221.

Rohrig, H., Schmidt, J., Miklashevichs, E., Schell, J., and John, M. 2002. Soybean ENOD40 encodes two peptides that bind to sucrose synthase. Proc. Natl. Acad. Sci. U.S.A. 99:1915-1920.

Rosso, M. N., Dubrana, M. P., Cimbolini, N., Jaubert, S., and Abad, P. 2005 Application of RNA interference to root-knot nematode genes encoding esophageal gland proteins. Mol. Plant-Microbe Interact. 18:615-620.

Sambrook, J., and Russell, D. W. 2001. Molecular Cloning: A Laboratory Manual. Cold Spring Harbor Laboratory Press, Cold Spring Harbor, NY, U.S.A.

Semblat, J. P., Rosso, M. N., Hussey, R.S., Abad, P., and CastagnoneSereno, P. 2001. Molecular cloning of a cDNA encoding an amphidsecreted putative avirulence protein from the root-knot nematode Meloidogyne incognita. Mol. Plant-Microbe Interact. 14:72-79.

Triantaphyllou, A. C. 1985. Cytogenetics, cytotaxonomy and phylogeny of root-knot nematodes. Pages 113-126 in: An Advanced Treatise on Meloidogyne, Vol. I. J. Sasser and C. Carter, eds. North Carolina University Graphics, Raleigh, NC, U.S.A.

Trudgill, D. L., and Blok, V. C. 2001. Apomictic, polyphagous root-knot nematodes: Exceptionally successful and damaging biotrophic root pathogens. Annu. Rev. Phytopathol. 39:53-77.

Tzortzakakis, E. A., Blok, V. C., Phillips, M. S., and Trudgill, D. L. 1999. Variation in root-knot nematode (Meloidogyne spp.) in Crete in relation to control with resistant tomato and pepper. Nematology 1:499-506.

Urwin, P. E., Lilley, C. J., and Atkinson, H. J. 2002. Ingestion of doublestranded RNA by preparasitic juvenile cyst nematodes leads to RNA interference. Mol. Plant-Microbe Interact. 15:747-752.

Vastenhouw, N. L., Brunschwig, K., Okihara, K. L., Muller, F., Tijsterman, M., and Plasterk, R. H. A. 2006. Long-term gene silencing by RNAi. Nature 442:882.

Vos, P., Hogers, R., Bleeker, M., Reijans, M., van de Lee, T., Hornes, M. Frijters, A., Pot, J., Peleman, J., Kuiper, M., and Zabeau, M. 1995. AFLP: a new technique for DNA fingerprinting. Nucleic Acids Res. 23:4407-4414.

Williamson, V. M., and Hussey, R. S. 1996. Nematode pathogenesis and resistance in plants. Plant Cell 8:1735-1745.

Williamson, V. M., and Kumar, A. 2006. Nematode resistance in plants: the battle underground. Trends Genet. 22:396-403.

$\mathrm{Xu}$, J. Narabu, T., Li, H., and Fu, P. 2002. Preparation of Meloidogyne javanica near-isogenic lines virulent and avirulent against the tomato resistance gene $M i$ and preliminary analyses of the genetic variation between the two lines. Acta Genet. Sin. 29:212-216. 